\title{
Time Point to Perform Lung Function Tests Evaluating the Effects of an Airway Clearance Therapy Session in Cystic Fibrosis
}

\author{
Maria Cecilia Rodriguez Hortal MSc and Lena Hjelte MD PhD
}

\begin{abstract}
BACKGROUND: Lung function parameters are used as end points in most clinical and therapeutic trials in cystic fibrosis (CF) and to evaluate the effects of airway clearance techniques. The aim of the study was to identify at what time point after a physiotherapy session spirometry $\left(\mathrm{FEV}_{1}\right.$ and FVC) should be performed to obtain the highest result compared to baseline and to determine whether there are inter-individual and intra-individual differences in children and adults with $\mathbf{C F}$. METHODS: This was a prospective study. Twenty-four subjects with $\mathrm{CF}$ and mean FVC $70 \pm 30 \%$ and $\mathrm{FEV}_{1} 61 \pm 30 \%$ of predicted were included. Each subject performed spirometry before their airway clearance session and then immediately after, 30 min after, and 1, 2, and $3 \mathrm{~h}$ after their physiotherapy session for 2 consecutive days. RESULTS: In adult subjects, mean FEV $_{1}$ improved $30 \mathrm{~min}(P<.001), 1 \mathrm{~h}(P<.002)$, and $2 \mathrm{~h}(P<.006)$ after physiotherapy compared to baseline. In pediatric subjects, it improved immediately after the session but was not statistically significant for recommendation. There were no intra-individual variations, but there were inter-individual variations (not statistically significant). CONCLUSIONS: Performing spirometry 30 min (adults) and immediately (children) after a session might be optimal if individual peak time values cannot be used. Key words: chest physiotherapy; cystic fibrosis; spirometry; time point. [Respir Care 2014;59(10):1537-1541. (c) 2014 Daedalus Enterprises]
\end{abstract}

\section{Introduction}

Cystic fibrosis (CF) is the most common, life-shortening, autosomal recessive, inherited disease affecting white people. ${ }^{1}$ The condition is caused by mutations in a single

\footnotetext{
The authors are affiliated with the Department of Clinical Science, Intervention and Technology, Karolinska Institutet, Stockholm, Sweden. Ms Rodriguez Hortal is affiliated with the Department of Physical Therapy, and Dr Hjelte is affiliated with the Stockholm Cystic Fibrosis Centre, Karolinska University Hospital, Stockholm, Sweden.
}

Ms Rodriguez Hortal presented a version of this paper at the 31st European Cystic Fibrosis Conference, held June 11-14, 2008, in Prague, Czech Republic.

This research was sponsored by the Swedish Order of Freemasons in Stockholm and the Samaritan Foundation. The authors have disclosed no other conflicts of interest.

Correspondence: Maria Cecilia Rodriguez Hortal MSc, Department of Physiotherapy R41, Karolinska University Hospital Huddinge, SE 141 86 Stockholm, Sweden. E-mail: cecilia.rodriguez-hortal@karolinska.se.

DOI: $10.4187 /$ respcare. 02823 gene on chromosome 7, which encodes the CF transmembrane conductance regulator (CFTR). The CFTR protein is a membrane-bound, cyclic adenosine $3^{\prime}, 5^{\prime}$-mono phosphate-regulated chloride channel that is thought to regulate other cell membrane ion channels. It is involved in water and electrolyte transport with secondary effects on many cellular functions. ${ }^{2}$ Clinically, the defect results in inappropriately thick, sticky mucus and malfunctioning of epithelial organs, such as lungs, pancreas, liver, sweat glands, and, in males, the Wolffian ducts. ${ }^{3}$ The 2 main clinical characteristics of $\mathrm{CF}$ are progressive pulmonary disease and pancreatic insufficiency. The former, associated with chronic bacterial infection, is the major cause of morbidity and mortality in CF patients.

The retention of mucus due to the impaired clearance of abnormally viscous airway secretions is a major feature of lung disease in CF. ${ }^{2}$ Promoting airway clearance using respiratory physiotherapy remains a mainstay of treatment for patients with CF. ${ }^{3}$ The aim of the respiratory physiotherapy is to mobilize and evacuate the major quantity of secretions, to maintain or improve pulmonary function to slow down disease progression, and to improve the quality of life. Evaluating the effects of the different airway clear- 
ance techniques offered for CF care is thus essential. Spirometry has been the accepted standard in disease monitoring, mostly forced expiratory maneuvers, such as $\mathrm{FEV}_{1}$ and FVC. ${ }^{4}$

There are standard recommendations from the European Respiratory Society (ERS) and the American Thoracic Society (ATS) ${ }^{2}$ about lung function tests and how spirometry should be performed. ${ }^{5,6}$ However, the ERS and ATS give no recommendations regarding the timing of spirometry in relation to physiotherapy, and to our knowledge, there are no studies investigating at what specific time point spirometry should be performed after a physiotherapy session. Thus, the time points to perform a lung function test after respiratory physiotherapy are still unclear.

The aim of the study was to identify at what time point after a physiotherapy session spirometry ( $\mathrm{FEV}_{1}$ and $\left.\mathrm{FVC}\right)$ should be performed to obtain the highest result compared to baseline and to determine whether there are inter-individual and intra-individual differences in children and adults with CF.

\section{Methods}

\section{Design of the Study}

The study was a prospective design. Spirometry was performed after a physiotherapy session for 2 consecutive $\mathrm{d}$ at different time points. The time points were arbitrarily chosen to obtain possible time-dependent results. The study was approved by the regional ethical review board in Stockholm, Sweden.

\section{Subjects}

Inclusion criteria were confirmed diagnosis of CF based on clinical features, $\geq 2$ positive sweat tests (chloride $>60 \mathrm{mmol} / \mathrm{L}),{ }^{7}$ and/or the presence of a known diseasecausing mutation on each CFTR gene. Exclusion criteria were upper airway infection, cognitive dysfunction, presence of nasal polyps, associated asthma, incapable of performing a technically acceptable lung function test, and no possibility to stay at the clinic for the required $4 \mathrm{~h}$. The subjects were included consecutively from the out-patient clinic of the Stockholm CF Center. Of the 28 subjects screened, 24 were enrolled in the study.

Informed consent was obtained from the adult and pediatric subjects participating in the study; when the pediatric subjects were $<18$ y of age, informed consent was obtained from their parents. Of the 24 subjects included, 16 were adults (mean age $32 \pm 9$ y) and 8 were children (mean age $15 \pm 2$ y) (Table 1).

\section{QUICK LOOK}

\section{Current knowledge}

Studies evaluating airway clearance in cystic fibrosis commonly use changes in lung function parameters (eg, $\mathrm{FEV}_{1}$ ) as clinical end points. The optimal timing to perform lung function studies following an intervention has not been elucidated.

\section{What this paper contributes to our knowledge}

The optimal time to perform spirometry following an airway clearance session varies between individual subjects but not within individuals. Optimal timing appears to be 30 min following airway clearance in adult subjects and immediately after lung clearance maneuvers in pediatric subjects.

\section{Procedures}

The daily physiotherapy performed by all subjects in the study, which was the standard treatment indicated by the physiotherapist and doctor according to age and lung function, consisted of inhalation twice each day with the following medications: $\beta_{2}$ agonist + hypertonic saline (12 adult subjects and one pediatric subject), $\beta_{2}$ agonist + acetylcysteine ( 4 adult and 6 pediatric subjects), and $\beta_{2}$ agonist + bromhexine (one pediatric subject). The daily respiratory physiotherapy (airway clearance techniques) performed by all subjects consisted of autogenic drainage for $10 \mathrm{~min}$, positive expiratory therapy for 10 breaths, and 3 huffing maneuvers. Autogenic drainage, positive expiratory therapy, and huffing were repeated 3 times according to recommendations from the International Physiotherapy Group for Cystic Fibrosis. ${ }^{8}$ No subject received recombinant human deoxyribonuclease, and all subjects had performed inhalation and respiratory physiotherapy since diagnosis.

The medication and respiratory treatment remained consistent for an individual subject during the study. Physiotherapy was performed in a sitting position at the same time of day for $2 \mathrm{~d}$, and the lung function test was performed in a sitting position at the same time of day for the study according to ATS/ERS recommendations (3 technically acceptable and reproducible efforts, maximum difference between the 2 best measurements of $5 \%$ or $150 \mathrm{~mL}) .^{5}$

Subjects performed spirometry with a portable microspirometer (MS01 Gold Standard MicroPlus, CareFusion, San Diego, California) before their airway clearance session and immediately after, $30 \mathrm{~min}$ after, and 1, 2, and $3 \mathrm{~h}$ after their airway clearance session. Spirometry was per- 
Table 1. Subjects' Characteristics at Inclusion

\begin{tabular}{lccc}
\hline \hline & $\begin{array}{c}\text { Adult } \\
\text { Subjects } \\
(n=16)\end{array}$ & $\begin{array}{c}\text { Pediatric } \\
\text { Subjects } \\
(n=8)\end{array}$ & $\begin{array}{c}\text { Total } \\
(n=24)\end{array}$ \\
\hline Age, mean $\pm \mathrm{SD}, \mathrm{y}$ & $32 \pm 9$ & $15 \pm 2$ & $26 \pm 10$ \\
Female/male, $n$ & $6 / 10$ & $1 / 7$ & $7 / 17$ \\
$\mathrm{FEV}_{1}$, mean $\pm \mathrm{SD}, \%$ predicted* & $56 \pm 29$ & $70 \pm 32$ & $61 \pm 30$ \\
$\mathrm{FVC}^{*}$ mean $\pm \mathrm{SD}, \%$ predicted* & $67 \pm 27$ & $76 \pm 37$ & $70 \pm 30$ \\
$\mathrm{FEV}_{1}<70 \%$ predicted, $n$ & 11 & 4 & 15 \\
Sputum producers, $n_{\text {Chronic pseudomonas colonization, } n} n$ & 16 & 6 & 22 \\
Diabetes, $n$ & 5 & 8 & 22 \\
& & 1 & 6
\end{tabular}

* Values are reference values based on sex, age, and height.

formed in a sitting position. $\mathrm{FEV}_{1}$ and $\mathrm{FVC}$ were taken as the best value out of the 3 technically satisfactory forced expirations. Lung function as percent of predicted was calculated from the reference values presented by Hedenström et al $^{9,10}(\geq 19 \mathrm{y})$ and by Solymar et $\mathrm{al}^{11,12}(<19 \mathrm{y})$. All subjects performed the series of measurements on 2 consecutive $d$ to identify intra-individual variations. No subjects withdrew from the study.

\section{Statistics}

A sample size of 17 will have $80 \%$ power to detect a difference in means of .05 assuming that the common SD is 0.480 using a single group $t$ test with a .05 significance level. The Student $t$ test was used to compare the paired data. Calculations were made with statistics software (Statistica 7.0, StatSoft, Tulsa, Oklahoma). $P$ values $<.05$ were considered significant.

\section{Results}

The mean $\mathrm{FEV}_{1}$ in adult subjects was increased after the physiotherapy session at each time point but was statistically significant $30 \mathrm{~min}(P<.001), 1 \mathrm{~h}(P<.002)$, and $2 \mathrm{~h}(P<.006)$ after physiotherapy in comparison to baseline. The mean FVC increase was statistically significant at $30 \mathrm{~min}(P<.02)$ and $2 \mathrm{~h}(P<.04)$ after physiotherapy. The mean $\mathrm{FEV}_{1}$ increase in adult subjects was $7 \%$ compared to baseline (30 min after physiotherapy). In comparison to baseline, the highest FVC mean increase was 10\% (30 min after physiotherapy) (Table 2 and Fig. 1).

The mean $\mathrm{FEV}_{1}$ and FVC in pediatric subjects showed no statistically significant difference from baseline at any time point, but there was a trend to increase immediately after physiotherapy (Table 2 and Fig. 1). The mean increase in $\mathrm{FEV}_{1}$ for pediatric subjects was $1 \%$ (immediately after physiotherapy) and in FVC was $2 \%$ (immediately after physiotherapy) compared to baseline. If we consider peak time in liters compared to baseline, mean $\mathrm{FEV}_{1}$ in adults increased by $11 \%$, and mean FVC in adults increased by $17 \%$. If we consider peak time in liters compared to baseline, mean $\mathrm{FEV}_{1}$ in children increased by $7 \%$, and mean FVC in children increased by $9 \%$. Furthermore, there were no intra-individual variations regarding peak time point.

\section{Discussion}

This is, to our knowledge, the first study investigating at what time point after chest physiotherapy spirometry should be performed. The main result was the difference in $\mathrm{FEV}_{1}$ in adult subjects, which depended on time point, from a mean of $56 \%$ (baseline) to $60 \%$ of predicted. Other main findings were that patients showed a different $\mathrm{FEV}_{1}$ after their physiotherapy sessions with inter-individual variations but not intra-individual variations. Also, there was a difference between adult and pediatric subjects.

Not taking time points after physiotherapy sessions into consideration in designing clinical and therapeutic studies may lead to underestimation as well as overestimation of outcome results. In most therapeutic studies, spirometry is performed at the same time of day by the individual subjects, thereby indirectly minimizing the effect of physiotherapy sessions, and it is not considered how chest physiotherapy could affect lung function test results. ${ }^{13}$ We have shown in this study that it is important to determine an individual subject's peak time point after physiotherapy, which may be of clinical importance. In evaluating the effect of different chest physiotherapeutic sessions, choosing the right time point for lung function tests might be considered.

Adult subjects showed a statistically significant improvement in mean $\mathrm{FEV}_{1}$ and $\mathrm{FVC}$ after 30 min and $2 \mathrm{~h}$, whereas pediatric subjects showed an improvement immediately after physiotherapy (not significant). Unexpectedly, there was a deterioration trend in $\mathrm{FEV}_{1}$ and FVC in pediatric subjects over time. Sixty-nine percent of adult subjects had a baseline $\mathrm{FEV}_{1}<70 \%$ of predicted, and $100 \%$ were sputum producers. The corresponding values for pediatric subjects were 50 and $75 \%$, respectively. Sputum producers were those subjects who expectorated $>25 \mathrm{~mL}$ during airway clearance. Due to the progression of the disease, a more severe disease status in adult CF subjects is to be expected. After a physiotherapy session, adult subjects may experience an obstruction of their airways, and sputum that has not been evacuated could remain in the central airways, possibly affecting the results of the spirometry. This could be a possible reason for adult subjects performing spirometry better $30 \mathrm{~min}$ or later following chest physiotherapy. Pediatric subjects may have performed spirometry better immediately after chest physiotherapy due to lesser amounts of sputum and better lung function at baseline. The fact that they performed slightly worse over time 
Table 2. Spirometry Values Before and After Chest Physiotherapy

\begin{tabular}{|c|c|c|c|c|c|c|}
\hline & $\begin{array}{l}\text { Adult Subjects } \\
\quad(n=16)\end{array}$ & $P$ & $\begin{array}{l}\text { Pediatric Subjects } \\
\quad(n=8)\end{array}$ & $P$ & $\begin{array}{c}\text { Total } \\
(n=24)\end{array}$ & $P$ \\
\hline \multicolumn{7}{|c|}{$\mathrm{FEV}_{1}$, mean $\pm \mathrm{SD}, \%$ of predicted } \\
\hline Before & $56 \pm 29$ & & $70 \pm 32$ & & $61 \pm 30$ & \\
\hline Immediately after & $58 \pm 30$ & .20 & $71 \pm 31$ & .69 & $63 \pm 30$ & .22 \\
\hline 30 min after & $60 \pm 30$ & $<.001$ & $66 \pm 32$ & .12 & $63 \pm 30$ & .33 \\
\hline $1 \mathrm{~h}$ after & $59 \pm 30$ & $<.002$ & $64 \pm 30$ & .11 & $61 \pm 30$ & .95 \\
\hline $2 \mathrm{~h}$ after & $58 \pm 30$ & $<.006$ & $68 \pm 32$ & .51 & $62 \pm 30$ & .26 \\
\hline $3 \mathrm{~h}$ after & $57 \pm 29$ & .39 & $67 \pm 28$ & .27 & $61 \pm 28$ & .51 \\
\hline \multicolumn{7}{|c|}{$\mathrm{FVC}$, mean $\pm \mathrm{SD}, \%$ of predicted } \\
\hline Before & $67 \pm 27$ & & $76 \pm 37$ & & $70 \pm 30$ & \\
\hline Immediately after & $69 \pm 28$ & .53 & $78 \pm 37$ & .12 & $72 \pm 31$ & .24 \\
\hline $30 \mathrm{~min}$ after & $74 \pm 27$ & $<.02$ & $74 \pm 32$ & .46 & $74 \pm 28$ & .08 \\
\hline $1 \mathrm{~h}$ after & $72 \pm 27$ & .10 & $75 \pm 32$ & .66 & $73 \pm 28$ & .22 \\
\hline $2 \mathrm{~h}$ after & $72 \pm 27$ & $<.04$ & $74 \pm 31$ & .38 & $72 \pm 28$ & .26 \\
\hline $3 \mathrm{~h}$ after & $71 \pm 27$ & .15 & $70 \pm 27$ & .16 & $70 \pm 26$ & .79 \\
\hline
\end{tabular}

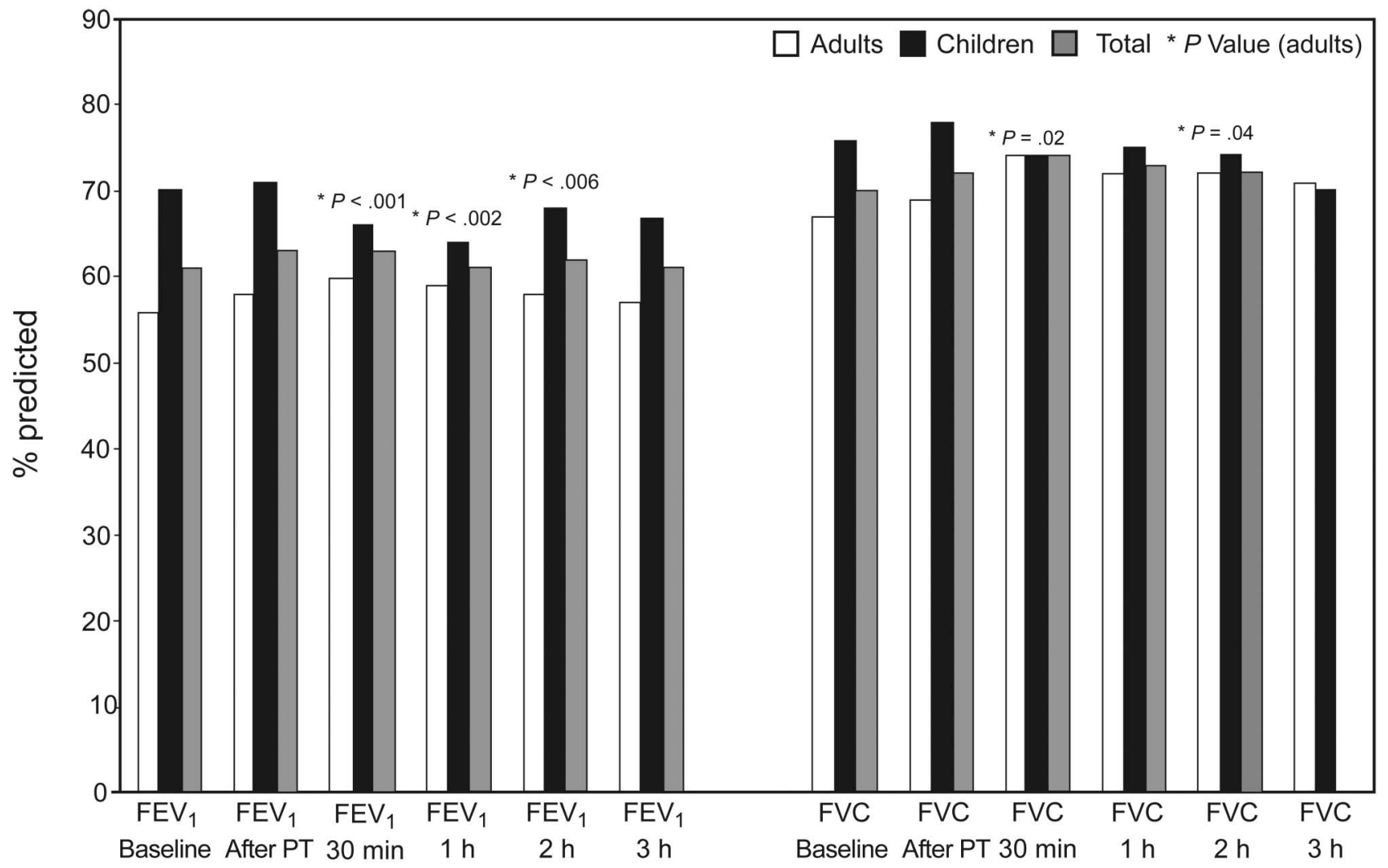

Fig. 1. Spirometry values and before and after chest physiotherapy (PT).

might be due to having to perform 18 spirometry maneuvers during the 3-h time period prior to chest physiotherapy. It might have been difficult for the pediatric subjects to stay highly motivated and to perform their very best repeatedly. Because the study was not designed to identify which factors might affect time points for peak performance after chest physiotherapy, more studies are necessary.

While observing individual subjects, it was noted that their increases in $\mathrm{FEV}_{1}$ after their physiotherapy sessions 


\section{Timing of Lung Function Tests Following Airway Clearance}

were higher at different time points. The intra-individual variations showed no difference.

The main limitation of the study was its size. It was not powered for subanalyses.

$\mathrm{FEV}_{1}$ is certainly one of the best and widely used markers of prognosis in CF. However, the measurements lack sensitivity, particularly in mild early stages of disease or when looking for small changes in response to an intervention.

Another limitation is that the subjects in the study were treated differently regarding inhaled medications, and therefore, this difference in treatment may influence the results.

In our study, we used spirometry because it is still one of the most used outcome parameters, and although highly technique-dependent and effort-dependent, it is easy to consecutively perform in an out-patient setting. Subjects in the study were used to performing spirometry every month from the age of 4-5 y.

Because of the arbitrary termination, we used spirometry (the highest value of the 3 technically satisfactory efforts). This may have underestimated the results, especially in those individuals who may have benefitted from a warm-up period.

Lung function parameters have been used as end points in most therapeutic trials in CF to date. It has been suggested that the lung clearance index could be a more sensitive early marker and a stronger indicator of disease progression than spirometry. ${ }^{14}$

$\mathrm{FEV}_{1}$ is still an important outcome parameter in clinical trials, and we believe that our findings are important and have to be taken into account in designing studies in the future.

\section{Conclusions}

The optimal time point to perform accurate spirometry after an airway clearance session varied between individual subjects with CF but not within individuals. However, there was a trend showing that performing spirometry immediately after the session for children and 30 min after the session for adults might be optimal (statistically significant), but individual peak time should also be considered.

\section{REFERENCES}

1. Dodge JA, Lewis PA. Cystic fibrosis is no longer an important cause of childhood death in the UK. Arch Dis Child 2005;90(5):547.

2. Matsui H, Grubb BR, Tarran R, Randell SH, Gatzy JT, Davis CW, Boucher RC. Evidence for periciliary liquid layer depletion, not abnormal ion composition, in the pathogenesis of cystic fibrosis airways disease. Cell 1998;95(7):1005-1015.

3. Pisi G, Chetta A. Airway clearance therapy in cystic fibrosis patients. Acta Biomed 2009;80(2):102-106.

4. Davies JC, Alton EW. Monitoring respiratory disease severity in cystic fibrosis. Respir Care 2009;54(5):606-617.

5. Miller MR, Crapo R, Hankinson J, Brusasco V, Burgos F, Casaburi $\mathrm{R}$, et al. General considerations for lung function testing. Eur Respir J 2005;26(1):153-161

6. Miller MR, Hankinson J, Brusasco V, Burgos F, Casaburi R, Coates A, et al. Standardisation of spirometry. Eur Respir J 2005;26(2):319338.

7. Gibson LE, Cooke RE. A test for concentration of electrolytes in sweat in cystic fibrosis of the pancreas utilizing pilocarpine by iontophoresis. Pediatrics 1959;23(3):545-549.

8. International Physiotherapy Group for Cystic Fibrosis. Physiotherapy for people with cystic fibrosis: from infant to adult. 2009. www. cfww.org/ipg-cf.

9. Hedenström H, Malmberg P, Agarwal K. Reference values for lung function tests in females. Regression equations with smoking variables. Bull Eur Physiopathol Respir 1985;21(6):551-557.

10. Hedenström H, Malmberg P, Fridriksson HV. Reference values for lung function tests in men: regression equations with smoking variables. Ups J Med Sci 1986;91(3):299-310.

11. Solymar L, Aronsson PH, Bake B, Bjure J. Nitrogen single breath test, flow-volume curves and spirometry in healthy children, 7-18 years of age. Eur J Respir Dis 1980;61(5):275-286.

12. Solymar L, Aronsson PH, Bake B, Bjure J. Respiratory resistance and impedance magnitude in healthy children aged $2-18$ years. Pediatr Pulmonol 1985;1(3):134-140.

13. McGarry ME, Nielson DW. Normalization of sweat chloride concentration and clinical improvement with ivacaftor in a patient with cystic fibrosis with mutation S549N. Chest 2013;144(4):13761378.

14. Aurora P, Bush A, Gustafsson P, Oliver C, Wallis C, Price J, et al. Multiple-breath washout as a marker of lung disease in preschool children with cystic fibrosis. Am J Respir Crit Care Med 2005; 171(3):249-256. 